\title{
PARTICIPACIÓN Y FRACASO DEL CATOLICISMO SOCIAL EN LOS ASUNTOS LABORALES EN MONTERREY, 1920-1926 ${ }^{1}$
}

PARTICIPATION AND FAILURE OF SOCIAL CATHOLICISM IN LABOR ISSUES IN MONTERREY, 1920-1926.

\author{
Luis Fidel Camacho Pérez ${ }^{2}$ \\ Universidad Autónoma de Nuevo León \\ DOI: $10.17533 /$ udea.tempus.n7a07
}

\section{Resumen}

Durante la primera mitad de la década de los 20, la Iglesia católica difundió dentro y fuera de las fábricas regiomontanas, las ideas de León XIII, teniendo un relativo éxito entre un sector de trabajadores compuesto principalmente por mujeres y niños. Sin embargo, la recepción de este ideario fue rechazado por los obreros de la gran industria.

Palabras clave: Relaciones laborales, Catolicismo Social, Monterrey, N.L., Sindicatos, Industria.

\begin{abstract}
:
During the first half of the decade of the 20's, the Catholic Church spread inside and outside the regional factories ideas of Leon XIII, having a relative success among a sector of workers composed mainly of women and children. However, the reception of this ideology was rejected by the workers of the big industry.
\end{abstract}

Keywords: Labor relations, Social Catholicism, Monterrey, N.L., Unions, Industry.

\section{Introducción}

La historiografía de la industrialización de Monterrey y de las relaciones obreropatronales que de ésta surgieron, han sido temas de una gran cantidad de investigaciones

\footnotetext{
1 Artículo recibido el 26 de febrero de 2018; aprobado el 18 de abril de 2018

${ }^{2}$ Licenciado En Historia y Estudios de Humanidades (FFYL, UANL). Adscripto Institucionalmente a Capilla Alfonsina Biblioteca Universitaria de la Universidad Autónoma de Nuevo León. Ciudad Universitaria, San Nicolás de los Garza, Nuevo León, Teléfono: 8117402197, correo electrónico:camacho77f@gmail.com
} 
realizadas desde distintos enfoques y posturas, ya sea a manera de crónica, de forma crítica u opositora, o bien con intereses meramente académicos ${ }^{3}$ sin embargo, la mayoría de las investigaciones ha dejado de lado el impacto de la enseñanza católico-social en dichas relaciones y se ha centrado en el llamado paternalismo y sindicalismo. Del mismo modo, la mayoría de los estudios ha ahondado en la Gran Industria, entiéndase por esto a las empresas del ramo siderúrgico y metalúrgico, así como la cervecería y la vidriera. No obstante, esta investigación no se limitará sólo a las grandes empresas, sino que también contemplará a las pequeñas y medianas.

Existen algunas investigaciones que han señalado la influencia de las encíclicas papales en la formación de un sistema de pensamiento empresarial y otras que las han descartado. Por ejemplo, Menno Vellinga, en su obra Desigualdad, poder y cambio social en Monterrey, afirmó que el ideario de los empresarios Garza Sada estuvo alimentado por las encíclicas Rerum Novarum y Quadragesimo Anno, de León XIII y Pío XI, respectivamente, en cuanto a temas como la familia, la religión y la propiedad privada ${ }^{4}$. Por otro lado, el estadunidense Michael Snodgrass negó tal influencia, al señalar que las prácticas laborales realizadas y promovidas en la Cervecería Cuauhtémoc tenían que ver con "políticas paternalistas ",5 aprendidas en los Estados Unidos.

No obstante, para los religiosos y laicos regiomontanos comprometidos con el Catolicismo Social, era fundamental que las clases sociales (obreros y empresarios) mantuvieran relaciones de cordialidad y de cooperación. Tanto la Asociación Católica de la Juventud Mexicana (ACJM), como la Unión de Damas Católicas Mexicanas (UDCM) buscaron la creación de círculos de obreros y centros de catecismo al interior y fuera de las fábricas, donde también repartían folletos y revistas que hablaban sobre la importancia de la cooperación de clases y de los sindicatos católicos.

\footnotetext{
${ }^{3}$ Algunos de los títulos sobre la temática son: Los orígenes de la Industrialización de Monterrey de Isidro Vizcaya y Burguesía, Capitales e Industria en el norte de México de Mario Cerutti, entre otros.

${ }^{4}$ Aunque Menno Vellinga señala la influencia de la Doctrina Social Católica no presenta evidencias que corroboren su aseveración. Véase: Vellinga, Desigualdad, 62.

${ }^{5}$ Snodgrass define al paternalismo como: aquellos incentivos no salariales para los trabajadores, Snodgrass, Deferencia, 2003, 77.
} 
Por lo que surgen algunas preguntas, como las siguientes: ¿hubo influencia de la Doctrina Social de la Iglesia en el sector empresarial u obrero de Monterrey?, ¿existieron círculos o sindicatos de obreros católicos?, ¿quiénes y cómo difundieron la Doctrina Social de la Iglesia? Para responder a estas cuestiones es importante reconocer que un gran número de empresarios y comerciantes regiomontanos (entre ellos los Garza, Calderón y Sada), tuvieron una activa participación en las asociaciones católicas desde finales del siglo XIX por medio de la Sociedad Católica de Señores y la Conferencia San Vicente de Paul, sociedades que se incorporaron en 1921 a la Orden de los Caballeros de Colón. Por otro lado, la UDCM de Monterrey era la asociación femenina donde militaban las esposas e hijas de los empresarios. Las prácticas (religiosas y de acción social) de estos grupos estaban ligadas a un sistema de normas y valores que constituían una representación social, ${ }^{6}$ que se venía configurado desde el siglo XIX.

Ambas sociedades tuvieron la colaboración de la ACJM y de clérigos comprometido con llevar a cabo la configuración de una cultura de trabajo y concordia, entre los obreros (niños, mujeres y varones) y empresarios, por medio de una serie de prácticas católicas específicas, como conferencias, catecismo y estudios de sociología cristiana. No obstante, la recepción del Catolicismo Social entre los obreros no fue la misma, sobre todo entre los trabajadores hombres, pues en determinado momento algunos de éstos, al igual que los agentes del gobierno, opusieron resistencia a las prácticas católicas al interior de las fábricas. Empero, quienes se apropiaron de este ideario fueron una élite compuesta por los principales empresarios de Monterrey, así como sus esposas.

Ahora bien, los círculos de obreros católicos en la ciudad de Monterrey no eran una novedad, pues ya existían desde principios de siglo, aunque casi con seguridad fueron disueltos en 1914. Ulteriormente, con la reconfiguración de la acción católica-social, resurgió también el deseo de agrupar a las multitudes de trabajadores católicos en torno a una agrupación que dirigiera a nivel nacional el curso de éstos, fue así como nació la

\footnotetext{
${ }^{6}$ Una representación social se configura cuando el individuo reconoce como suya una o varias prácticas (en este caso la acción católico-social), pues le aparece aceptable en relación con su sistema de valores. Véase: Abric, Prácticas, 198.
} 
Confederación Católica del Trabajo (CCT) en 1920, que posteriormente pasaría a llamarse Confederación Nacional Católica del Trabajo (CNCT).

Un año después de haber sido creada la CCT, celebró en Guadalajara una convención junto con los obreros libres. ${ }^{7}$ Tras cuatro días de conferencias se llegó al acuerdo de que, tanto obreros católicos como libres, aceptarían guiarse por los principios de la Rerum Novarum; de acuerdo con Manuel Ceballos, los obreros libres de las ciudades de Monterrey y Saltillo estuvieron representados por Julián Morales, quien iba como delegado de las empresas textiles "El Porvenir" y "La Leona”, y de la Cervecería Cuauhtémoc. ${ }^{8}$ Inclusive el mismo autor señala que, como resultado de la convención de 1921, libres y católicos realizaron una gira en marzo de 1922 con la intención de promover la creación de sindicatos adheridos a la CCT para que participaran en el Congreso Nacional Obrero que se celebraría al año siguiente, ${ }^{9}$ siendo Monterrey uno de los lugares visitados.

Aunque Julián Morales representó a los obreros libres de Monterrey y Saltillo, no se sabe con exactitud si las empresas apoyaron o se opusieron a la idea de que sus obreros estuvieran representados en un congreso de trabajadores católicos, y ni tampoco se puede determinar si representaba a todos los trabajadores o sólo a una fracción de éstos. Cabe mencionar que los dueños de la Cervecería Cuauhtémoc y "El Porvenir"10 tenían principios religiosos y morales que compaginaban con la enseñanza de León XIII, y constantemente participaron en obras de acción social, además de que al interior de sus empresas se practicaron celebraciones religiosas. Por otro lado, hay que agregar cuando la delegación de obreros católicos estuvo en Monterrey en marzo de 1922, ésta aprovechó para protestar contra un suceso acaecido en 1921 en Guadalajara, donde hubo un enfrentamiento entre un grupo de trabajadores católicos y un Sindicato de Inquilinos dirigido por el anarquista Jenaro Laurito, resultando cuatro obreros católicos muertos. ${ }^{11}$

\footnotetext{
7 “Los obreros libres eran una fracción separada del sindicalismo mexicano que no había optado por la CROM (fundada en 1918), ni por la CGT (fundada en 1921)”. Véase: Ceballos, Historia, 77.

${ }^{8}$ El Archivo social, 1 de noviembre de 1921, citado en Ceballos, Historia, 2004, 78.

${ }^{9}$ Ceballos, Historia, 79.

${ }^{10}$ El principal accionista de la Cervecería era Isaac Garza, quien pertenecía a la Asamblea Gral. de $4^{\circ}$ Grado "Fray Antonio de Jesús Sacedón”, y en la fábrica "El Porvenir" estaba Valentín Rivero Fernández, miembro de la mesa directiva del Consejo de Nuestra Señora de Monterrey No. 2312, ambas agrupaciones adyacentes a la Orden de los Caballeros de Colón; véase: Álbum, 16.

${ }^{11}$ Ceballos, Historia, 81.
} 


\section{La Doctrina católica al interior del taller}

A nivel local, existen algunos ejemplos de las celebraciones de culto católico dentro las fábricas fueron las realizadas al interior de Cervecería Cuauhtémoc y Fundidora. ${ }^{12}$ Ambas empresas fueron acusadas ante el gobernador de celebrar dichos actos (infringiendo el artículo 24 de la Constitución), por lo que el Departamento de Justicia, Instrucción Pública, Fomento y Guerra giró en junio de 1922 los oficios correspondientes a ambas empresas, prohibiéndoles la práctica del culto católico. Por su parte, el departamento legal de la Cervecería, representado por Lázaro de la Garza, señaló como falsas las acusaciones, además argumentó que "todo hombre es libre de practicar las ceremonias o cultos respectivos en sus domicilios particulares, pues lo que está prohibido son los cultos públicos destinados únicamente a los templos". ${ }^{13}$

Asimismo, la Fundidora mencionó que las denuncias eran inexactas, pues una de las reglas de la empresa era la "prohibición absoluta de la celebración de actos de carácter religioso o político”. No obstante, señaló que un gran número de los habitantes de la colonia Acero (en un escrito del 9 de mayo de 1922) solicitó a la empresa un local donde se pudiera practicar el culto católico los domingos y días festivos (pues quedaban muy lejos los templos de la ciudad). Ante esto, la Dirección accedió, prestándoles un local provisional mientras se construía una capilla, que de acuerdo con la empresa sería enteramente privada para no infringir la ley. ${ }^{14}$ Cabe mencionar que desde 1921 la Iglesia tenía establecido un centro de catecismo en dicha colonia. ${ }^{15}$ Al no recibir contestación del Ejecutivo del estado, la Compañía Fundidora giró dos cartas más, una en septiembre y otra en octubre, obteniendo respuesta hasta noviembre. En su resolución el gobierno indicaba no tener ningún problema con la celebración de actos religiosos al interior de la Colonia Acero. ${ }^{16}$

Por otro lado, la doctrina cristiana impartida por medio del catecismo, además de enseñarse en los colegios católicos, asilos y cárceles, también se introdujo dentro de las

\footnotetext{
${ }^{12}$ La cantidad de casos presentados en la investigación son proporcionales a las evidencias encontradas en las fuentes de archivos.

${ }^{13}$ AHENL, Asuntos Eclesiásticos (Religión), caja 5, exp. 2.

${ }^{14}$ AHENL, Asuntos Eclesiásticos (Religión), caja 5, exp. 2.

${ }^{15}$ AHAM, Boletín Eclesiástico, año 2, no. 8, agosto de 1921.

${ }^{16}$ AHENL, Asuntos Eclesiásticos (Religión), caja 5, exp. 2.
} 
fábricas. Esto pudo ser posible debido a las acciones de la Sección 2a. de la UDCM. Los primeros centros de catecismo de la Sección ubicados al interior de las empresas, estaban en la fábrica de dulces "La Corona" y en la fábrica "La Industrial", ${ }^{17}$ ésta última propiedad de Rafael Pozas; éste último centro fue inaugurado por 15 catequistas, teniendo una asistencia de 150 niños. ${ }^{18}$ Posteriormente se creó un centro en la fábrica de bebidas Topo Chico, el cual contaba con 80 niños y 7 catequistas. ${ }^{19}$ Generalmente los centros de catecismo de estas fábricas estaban integrados por niños y algunas mujeres, aunque las fuentes no precisan si éstos eran trabajadores de las mismas o sólo asistentes y catequistas.

Asimismo, en diversas ocasiones las empresas prestaron sus instalaciones para realizar actividades de recreación para los niños miembros de estos centros de catecismo, tales son los casos de las celebraciones realizadas en la Quinta Calderón y en el Parque de la Cervecería Cuauhtémoc. En el primer recinto se efectuó una fiesta en honor a los papeleros (niños vendedores de periódicos) en enero de 1923, teniendo una asistencia de 200 niños. ${ }^{20}$ En el segundo caso, se reunieron cerca de 800 niños de ambos sexos con motivo de las celebraciones navideñas, ahí se les repartieron ropa, juguetes y dulces; además, las catequistas también recibieron como obsequio un vestido, y dichos repartos estuvieron presididos por el arzobispo José Juan de Jesús Herrera y Piña y por el presbítero Antonio de P. Ríos. Cabe mencionar que Francisco Sada, además de haber facilitado el Parque, donó $\$ 100$ pesos para las actividades. ${ }^{21}$

De igual modo, la ACJM también mostró su interés en la creación de círculos de obreros y, en este sentido, es importante señalar que el círculo "Ozanam”, subgrupo de la Congregación Mariana del Roble, intentó formar un comité de obreros en el barrio de la Vidriera, colonia creada por la empresa del mismo nombre para sus trabajadores. Aun y con los intentos de dicho grupo católico, el comité nunca se pudo concretar, debido a la apatía

\footnotetext{
${ }^{17}$ El reporte mensual de la Sección 2a. las damas católicas no especifica a qué fábrica "La Industrial" hacen referencia, pues a principios de la década de 1920, existían tres empresas que llevaban ese nombre, una productora de galletas (Lara-Santos), otra dedicada a la elaboración de azulejos y mosaicos (V. Rivero Sucs.) y por último una textilera (Jesús Ferrara); no obstante en los tres casos las empresas pertenecían a empresarios integrados a la Orden de los Caballeros de Colón, véase: Álbum, 17- 20.

${ }^{18}$ Acción, Monterrey, N.L., noviembre de 1922, año 1, números 6 y 7.

${ }^{19}$ Acción, Monterrey, N.L., abril de 1924, año 3, no. 4,

${ }^{20}$ Acción, febrero de 1923, año 2, no. 2.

${ }^{21}$ Acción, enero de 1924, año 3, no. 1.
} 
que, según los propios miembros de "Ozanam”, veían en los obreros. ${ }^{22}$ Por su parte, el Grupo "León XIII" estableció un círculo de estudios que realizaba festivales de propaganda católico-social, a los que asistían en su mayoría obreros y donde se les impartía instrucción moral e intelectual. ${ }^{23}$

Ahora bien, lo ocurrido en el barrio de la Vidriera no fue un hecho aislado, pues hubo otros sitios en donde los obreros se mostraron desinteresados ante la idea de que la religión católica permeara dentro de sus espacios de trabajo. Otro caso similar fue el ocurrido en la fábrica de Hilados y Tejidos "La Industrial”, donde el sindicato de dicha empresa, además de mostrarse reacio al catolicismo, acusó al dueño de la empresa, Jesús Ferrara, ${ }^{24}$ con el gobernador interino, Anastasio Treviño Martínez, de permitir la constante afluencia de las Damas Católicas y de sacerdotes que practicaban el culto católico de forma pública, lesionando el artículo 24 de la Constitución. Asimismo, señalaron que dichas damas habían trasladado a bordo de ocho camiones a "las obreras y operarios fanatizados", al templo de la Trinidad en mayo de 1923, ${ }^{25}$ el cual como se mencionó líneas arriba, fue un año de intensos trabajos en el ámbito católico-social en la ciudad. De acuerdo con la misma queja, la presencia de los sacerdotes y de la UDCM dentro de la empresa fue un intento del dueño y del gerente de la fábrica (Genovevo L. Ramírez), para destruir al sindicato que tenía apenas diez meses de existencia.

Estos eventos dejan entrever la clara intención que tenían laicos y religiosos de introducir la Doctrina Social Católica dentro de las empresas; aunque al parecer dichas ideas fueron recibidas de mejor forma por niños y mujeres, pues tal recepción dio pie para la creación de la Unión de Empleadas Católicas Regiomontanas y la Unión del Magisterio Católico Regiomontano (1923), y el Sindicato de Papeleros y Boleros (1924).

En ese sentido, las damas católicas de Monterrey establecieron en diciembre de 1922, en la calle Hidalgo no. 136, la Casa-Familia para señoritas estudiantes y oficinistas, bajo la coordinación de la Sección 14a. de la UDCM. Contaba con habitaciones bien amuebladas,

\footnotetext{
22 Álbum, 24.

${ }^{23}$ Álbum, 24.

${ }^{24}$ Jesús Ferrara era miembro de la Asamblea Gral. de $4^{\circ}$ Grado "Fray Antonio de Jesús Sacedón” de la Orden de los Caballeros de Colón.

${ }^{25}$ AHENL, Trabajo, Asociaciones y Sindicatos (1921-1923), caja 5, exp. 4.
} 
alumbrado, ventilación y aseo, baños, servicio de luz, lavado y planchado de ropa y alimentación. ${ }^{26}$ Durante su inauguración al año siguiente se bendijo la casa y se entronizó una imagen del Sagrado Corazón de Jesús, y quien ofició los actos fue el arzobispo Herrera y Piña, con asistencia de los canónigos Pablo Cervantes y Rafael Plancarte, y de las mesas directivas de los Caballeros de Colón, de la ACJM y de la Unión de Empleadas Católicas Regiomontanas. ${ }^{27}$ Asimismo, la Casa-Familia contaba con servicios de caja de ahorros, préstamos, clases y una cooperativa de consumo. ${ }^{28}$

Por otro lado, el año de 1923 trajo consigo una serie de conferencias que, además de brindar una enseñanza teórica, también tuvo repercusiones prácticas e inmediatas, tal fue el caso de la Semana Social para religiosos. De modo que los sacerdotes concurrentes decidieron establecer una cooperativa de consumo para el clero, en la que se formaría un pequeño capital con base en acciones con valor de $\$ 50.00$ pesos cada una. Para su administración se acordó nombrar a un gerente seglar de confianza a cuyo cargo estaría la sociedad; sin embargo, su dirección pertenecería a un consejo directivo provisional formado por Juan José Hinojosa (presidente), Fortino Gómez y Heleno Salazar (vocales). ${ }^{29}$ Los estatutos de la cooperativa fueron escritos por Alfredo Méndez Medina y Rafael Plancarte, y fueron aprobados por el arzobispo. ${ }^{30}$

De igual forma, la UDCM propuso establecer entre las socias una Caja de Ahorro y Pequeños Préstamos para beneficio único de las mismas. En ese sentido, las damas católicas en una asamblea extraordinaria, en el edificio de los Caballero de Colón, presentaron el proyecto que fue aprobado; asimismo, el auxiliar eclesiástico dio una plática sobre el significado del ahorro, estableciéndose así la "Providencia", Caja de Ahorros y Pequeños Préstamos de la UDCM de Monterrey. ${ }^{31}$

\footnotetext{
${ }^{26}$ Acción, enero de 1923, año 2, no 1.

${ }^{27}$ Acción, febrero de 1923, año 2, no. 2.

${ }^{28}$ Patience Schell, "Las mujeres católicas del catolicismo social, 1912-1926", en: Ceballos, Manuel (coord.), en Catolicismo Social en México. Las Instituciones, Tomo II (México: Instituto Mexicano de Doctrina Social Cristiana/Academia de Investigación Humanística, 2005) 270.

${ }^{29}$ AHAM, Boletín Eclesiástico, año 4, no.12, diciembre de 1923.

${ }^{30}$ AHAM, Boletín Eclesiástico, año 5, no. 1, enero de 1924.

${ }^{31}$ Acción, julio de 1924, año 3, no. 7.
} 
El éxito que obtuvieron las damas católicas entre niños y mujeres en materia laboral las llevó a crear una Sección más, la Sección 6a. del Trabajo en febrero de 1924, “encargada de fomentar entre los niños el espíritu de unión y así conseguir su elevación moral, intelectual y económica" 32 . Durante una junta en febrero, las socias de la Sección recibieron una introducción sobre estudios sociales por parte de Rafael Plancarte, quien también les explicó lo que era un sindicato o unión profesional. ${ }^{33}$ Los trabajos de la Sección se enfocaron en adoctrinar a los niños pertenecientes a los centros de catecismo y escuelas católicas, donde les enseñaban lo que era un sindicato y una caja de ahorro, ${ }^{34}$ haciéndoles ver sus beneficios.

Tales fueron los trabajos de la nueva Sección que para mayo ya estaban elaborados los estatutos del sindicato de trabajadores infantiles. Se dividieron en cuatro capítulos: el primero hablaba sobre los objetivos del mismo, que eran el mejoramiento moral, intelectual y económico de sus socios; el segundo tenía que ver con los requisitos de los socios, como ser católico, ser mayores de siete años y contar con el consentimiento de sus padres o tutores; el capítulo tres hablaba sobre su organización, pues tenía que contar con una mesa directiva compuesta por niños, y finalmente el cuarto capítulo trataba sobre la cooperativa de consumo, donde los niños podrían acceder a material escolar, prendas de vestir, dulces y "objetos propios de su edad", entre otras cosas. Además, los niños tenían que pagar una cuota de inscripción de cinco centavos, y se estableció una Caja de Préstamos y Ahorro, que facilitaría préstamos a sus socios por la cantidad de hasta $\$ 3$ pesos. ${ }^{35}$

Sin embargo, fue hasta septiembre en que quedó establecido el sindicato Unión de Papeleros y Boleros, con 30 niños, pero en febrero de 1925 contando ya con 63 socios. $^{36}$ Durante la inauguración, recibieron un discurso impartido por el padre Enrique Tomás Lozano. Por su parte, la mesa directiva de los papeleros y boleros quedó de la siguiente manera: presidente Raymundo Candía, vicepresidente Serapio Villarreal y secretario Rogelio Franco. Junto con la Unión también fue creada la Escuela de la Unión de Papeleros, donde

\footnotetext{
${ }^{32}$ Acción, agosto de 1924, año 3, no. 8.

${ }^{33}$ Acción, marzo de 1924, año 3, no. 3.

${ }^{34}$ Acción, abril de 1924, año 3, no. 4.

${ }^{35}$ Acción, mayo de 1924, año 3, no. 5.

${ }^{36}$ Acción, febrero de 1925, año 4, no. 2.
} 
se les impartirían clases de primero y segundo grado, quedando como directora la señorita profesora Guadalupe Bernal.

Para la creación del colegio se recibieron apoyos del padre Plancarte, quien facilitó los pupitres; asimismo, las bancas fueron donadas por la Unión del Magisterio Católico Regiomontano; es importante señalar que la escuela se sostenía en gran parte con cooperaciones de los diarios El Porvenir y El Sol, ${ }^{37}$ cuyos directivos previamente se habían reunido con las socias de la UDCM Batilde Garza Sanmiguel, Leonarda Paz y Cesárea M. de González, para coordinar la colaboración. Asimismo, la apertura de la escuela estuvo autorizada por la Dirección General de Instrucción Primaria. ${ }^{38}$ El mencionado apoyo de los periódicos resulta interesante porque deja entrever que los principales diarios de ese entonces, que daban empleo a los niños papeleros, no veían amenazados sus intereses de clase ni por el clero, ni por las damas católicas, mucho menos por los niños, pues los estatutos del sindicato infantil estaban orientados a la concordia y no a la lucha.

Cabe agregar que la Unión de Papeleros y Boleros y la Unión del Magisterio Católico Regiomontano tuvieron como sede la casa central de la UDCM; asimismo, el surgimiento del sindicato católico magisterial y de la Unión de Empleadas Católicas Regiomontanas fue resultado de los trabajos sociales realizados en Nuevo León por el padre Alfredo Méndez Medina en 1923. Además, es pertinente destacar que para marzo de 1925 la mesa directiva de la Unión del Magisterio Regiomontano, estaba integrada por las profesoras: Pura Colunga, presidenta; María Antonia Carrillo, secretaria; Adela Castaño, prosecretaria; Virginia Villarreal, tesorera; Petra Villarreal, pro tesorera; María de Jesús Salinas y Guadalupe García Leal, vocales. ${ }^{39}$

La creación de estas uniones permite dilucidar que los católicos activos en materia social no sólo se preocupaban por los pobres y obreros, sino también por los empleados, profesionistas y maestros, pues algunos de éstos trabajaban en los colegios católicos y en las empresas en las que los dueños tenían acentuados principios religiosos. En ese sentido, para las mujeres católicas era importante la existencia de las uniones profesionales, como las antes

\footnotetext{
${ }^{37}$ Acción, octubre de 1924, año 3, no. 10.

${ }^{38}$ Acción, julio de 1924, año 3, no. 7, y noviembre de 1924, año 3, no. 11.

${ }^{39}$ Acción, marzo de 1925, año 4, no. 3.
} 
mencionadas, pues opinaban lo siguiente acerca de éstas: "convencidas estamos, de la necesidad que hay de la organización social, según la clase y profesión, para elevar el nivel religioso, moral, económico y profesional de los miembros de la sociedad" 40

Para ello, la CNCT había integrado en sus filas a "una serie de agrupaciones laborales que tenían características muy heterogéneas: empleados, artesanos, obreros de fábricas textiles, mineros, gran cantidad de campesinos, sindicatos de mujeres e incluso de niños" ${ }^{41}$ Esta diversidad permitió el crecimiento de la CNCT. A decir de Manuel Ceballos, se multiplicaron los sindicatos y las asociaciones filiales a los sindicatos: cooperativas de compra y venta, sociedades mutualistas, círculos de estudio, cajas de ahorro, bolsas de trabajo, escuelas, así como casas de hospedaje, ${ }^{42}$ como el caso de la Casa-Familia de Monterrey. De acuerdo con el mismo autor, Monterrey era una de las diócesis que tenía asociaciones adscritas a la CNCT, y es probable que fuera el caso de la cooperativa del clero, las uniones de empleadas y del magisterio católico regiomontano, y el sindicato de niños (papeleros y boleros).

No obstante, la indiferencia y resistencia a la influencia del Catolicismo Social en asuntos laborales por parte de los trabajadores (varones), pudo deberse a una diversidad de factores. Este análisis plantea la conjugación de dos variables: primero, la propagación de ideas sindicalistas combativas en algunas empresas; por ejemplo, en Cervecería Cuauhtémoc el intento de sindicalización produjo el despido de los dirigentes del movimiento en 1917, mientras que en Vidriera Monterrey un grupo de líderes de los trabajadores del vidrio, encabezados por Juan F. Flores y Juan M. Pardo, formaron el "Sindicato de Obreros de la Vidriera de Monterrey" en febrero de $1923 .{ }^{43}$

De igual forma, los obreros de la fábrica textil "La Industrial" se organizaron para crear un sindicato en ese mismo año tras el despido de 16 operarios hilanderos (conflicto resuelto por la intervención del gobernador Tamez y la Federación Regional de Sociedades Obreras); sin embargo, la empresa buscó por diversos medios su total desintegración, a través

\footnotetext{
${ }^{40}$ Acción, abril de 1924, año 3, no. 4.

${ }^{41}$ Ceballos, Historia, 90.

${ }^{42}$ Ceballos, Historia, 91.

${ }^{43}$ AHENL, Trabajo, Asociaciones y Sindicatos (1921-1923), caja 5, exp. 4.
} 
de la introducción de ideas del Catolicismo Social, del paro de labores que dejó a los hilanderos sin empleo; además, les obligó a firmar un contrato de arrendamiento en el que acordaban desocupar las viviendas que la empresa les había provisto si no pagaban mensualmente una renta de 25 centavos. Asimismo, la empresa despidió "injustificadamente" a los miembros del sindicato. ${ }^{44}$

El segundo factor implica el hecho de que los trabajadores regiomontanos encontraron en las organizaciones cooperativas de tendencia corporativa y sin sustento religioso alguno, la respuesta a sus necesidades y demandas más primordiales e inmediatas, como la salud, la vivienda, la educación y la recreación, en empresas como la Cervecería Cuauhtémoc y la Fundidora Monterrey, como fue el caso de la Sociedad Cooperativa y de Ahorro para Empleados y Operarios de la Cervecería Cuauhtémoc, creada en 1918. Por otro lado, desde mediados de los años 20 diversos factores, como el ascenso del sindicalismo oficial y los conflictos religiosos, generaron la decadencia de las asociaciones católicas de trabajadores a nivel nacional, en particular la CNCT.

Es decir, si bien las asociaciones católicas laicas difundieron su programa social en todo el país durante la primera mitad de los años 20, esta expansión comenzó a enfrentarse al llamado jacobinismo gubernamental, especialmente tras el ascenso de Plutarco Elías Calles a la presidencia a fines de 1924. Así, Luis N. Morones, líder de la CROM, impulsó en 1925 la creación de la iglesia cismática mexicana (ya antes mencionada), como una forma de contrarrestar las actividades religiosas en materia laboral, pues la CNCT comenzó a preocupar al gobierno, ya que para 1926 agrupaba a poco más de 22 mil trabajadores rurales y urbanos. ${ }^{45}$

La creación de la Iglesia Católica Apostólica Mexicana detonó la conformación de la Liga Nacional para la Defensa de la Libertad Religiosa (LNDLR), agrupación de carácter beligerante fundada por el jesuita Bernardo Bergöend. Además, en 1926 el gobierno ordenó

\footnotetext{
${ }^{44}$ Entre los desocupados y desalojados de "La Industrial" se encontraban los hilanderos: Ventura Velasco, Maximiliano Tamez, Manuel Torres, Joel Cisneros y Guadalupe Juárez, entre otros, en: AHENL, Trabajo, Asociaciones y Sindicatos (1921-1923), caja 5, exp. 4.

${ }^{45}$ Ceballos, Historia, 33.
} 
la expulsión de 200 clérigos de origen extranjero, la clausura de varios conventos y templos, el destierro de diversos obispos y el encarcelamiento de algunos sacerdotes. ${ }^{46}$

Asimismo, cabe señalar que el padre Méndez Medina había abandonado su cargo al frente del Secretariado Social Mexicano en 1925. De acuerdo con Ceballos, su ausencia debilitó la organización interna del CNCT, pues si bien éste "no intervenía en las decisiones directas del Comité Central, era su principal consultor y su mejor apoyo" ${ }^{47}$ La renuncia de Méndez Medina al SSM significó una ruptura en las actividades sociales que se hacían en toda la República, como fue el caso de los múltiples congresos católicos que llevó a cabo en la ciudad de Monterrey entre 1921 y 1924, generándose una discontinuidad en la difusión de la enseñanza social.

Entretanto, en Nuevo León tuvieron lugar en mayo de 1925 dos pronunciamientos públicos de los miembros de la ACJM contra el anticlericalismo gubernamental, donde se manifestaba su postura beligerante al criticar la actitud pasiva tomada por la Iglesia mexicana; asimismo, la UDCM mandó una misiva al presidente Calles pidiéndole que detuviera el avance del cisma de Morones. En cambio, los Caballeros de Colón no realizaron ninguna protesta contra las medidas del gobierno que eran contrarias a la Iglesia, quizá porque su función era más bien generar un soporte económico para las acciones realizadas por las asociaciones antes mencionadas, pero sin poner en riesgo sus empresas.

Al año siguiente, un intento de boicot económico llevado a cabo a nivel nacional por la LNDLR no tuvo el éxito esperado y los organizadores de la iniciativa fueron apresados, entre ellos los prelados José Mora y del Río y Pascual Díaz, así como René Capistrán Garza, fundador de la ACJM. ${ }^{48}$ Después de estos sucesos, todos los arzobispos y obispos mexicanos publicaron en el mes de julio de 1926 la Carta Pastoral Colectiva donde anunciaban la suspensión de cultos a nivel nacional, como reacción a la hostilidad del gobierno. ${ }^{49}$

\footnotetext{
46 Moisés Saldaña Martínez, El anticlericalismo oficial en Nuevo León, 1924-1936, Monterrey (Nuevo León: Facultad de Filosofía y Letras, Universidad Autónoma de Nuevo León, 2009) 97.

${ }^{47}$ Ceballos, Historia, 106.

${ }^{48}$ Aguilar Camín y Meyer, A la sombra, 102.

${ }^{49}$ Saldaña, Anticlericalismo, 99.
} 
A finales de ese mismo mes entró en vigor la llamada Ley Calles, o Ley de Cultos, legitimando las disposiciones que el gobierno venía tomando en contra de la Iglesia católica, y que "además establecía el registro obligatorio de todos los sacerdotes ante la Secretaría de Gobernación". ${ }^{50}$ Con este par de acciones se abría la puerta para el inicio del conflicto cristero, que perduró hasta 1929, el cual fue organizado y auspiciado principalmente por la LNDLR, y estuvo espacialmente ubicado en los sectores mayoritariamente rurales. Como resultado de este conflicto, la participación de la Iglesia en la organización obrera cesó oficialmente.

De tal modo, la CNCT fue disuelta en 1931 tras promulgarse la Ley Federal del Trabajo, que desconocía a los sindicatos confesionales. En ese sentido, el relativo éxito de las uniones de profesionales y el sindicato de niños en Monterrey se vio interrumpido, debido a las disposiciones gubernamentales que proscribieron a todo sindicalismo religioso. ${ }^{51} \mathrm{Sin}$ embargo, cabe agregar que la herencia del sindicalismo católico se mantuvo viva, ya que en 1936 se creó en Monterrey la Federación Nacional de Sindicatos Independientes (el llamado "sindicalismo blanco"), que integraba a trabajadores de diversas empresas regiomontanas y que implicaba algunos rasgos de la doctrina social católica, aunque sin hacerlos explícitos. ${ }^{52}$

De tal modo, la Iglesia se vio obligada a sustraerse de la participación en la organización de los trabajadores y ello menguó su acción social en el nivel popular. No obstante, las actividades sociales de los católicos no cesaron, sino que debieron pasar a ser más disimuladas (por las prohibiciones legales o los ambientes persecutorios, como en los años 30). Por otro lado, muchas de las asociaciones católicas pasaron a integrarse a la Acción Católica Mexicana, creada en 1929, o se abocaron casi exclusivamente hacia las prácticas devocionales (como la Adoración Nocturna o la Asociación del Santísimo). Asimismo, se consolidó un catolicismo de corte elitista, conservador y reaccionario, ligado a los grupos de poder económico en Monterrey, el cual se forjó por las circunstancias de los años 30.

\section{Consideraciones finales}

\footnotetext{
${ }^{50}$ Saldaña, Anticlericalismo, 99.

${ }^{51}$ Ceballos, Sindicalismo, 653-666.

52 Blancarte, Historia, 136.
} 
El surgimiento de las asociaciones católicas con vocación social en Monterrey, demuestra la insistencia de la Iglesia por intervenir en la dirección de la sociedad. La importancia de su participación social radicó en la formación de instituciones de diversa naturaleza durante la primera mitad de la década de los 20, las cuales buscaron el beneficio y desarrollo de la clase baja. En dicho contexto, la propuesta de León XIII, adaptada a las circunstancias mexicanas y, específicamente, a las regiomontanas, debió coexistir y competir con la ideología emanada de la Revolución.

De modo que durante ese periodo tuvo un gran auge en la Arquidiócesis de Monterrey la difusión y enseñanza del Catolicismo Social, que lejos de quedarse meramente en una teoría o discurso, se pudo poner en práctica. Además de los congresos y jornadas sociales, los Comités Regionales de la ACJM, UDCM y Caballeros de Colón, así como sus grupos locales, círculos y secciones, recibían, leían y distribuían las publicaciones oficiales de las asociaciones católicas laicas, como Alma Fronteriza, Juventud Católica, Acción y la Hoja Dominical, por mencionar sólo algunas, donde no sólo registraban sus labores, sino que también se difundía la acción social.

Por otra parte, estas asociaciones impulsoras del Catolicismo Social en Monterrey procuraron mantener unificados y controlados a sus grupos locales, por medio de una serie acciones y prácticas religiosas determinadas, como la jerarquía organizativa y la recepción constante de los sacramentos; además, organizaban círculos de estudios sobre temas apologéticos y sociológicos, en los cuales se fomentaban y sostenían las obras sociales. Actividades en las que colaboraban activamente los sacerdotes Juan José Hinojosa, Pablo Cervantes, Rafael Plancarte y Tomas M. del Campo, entre otros.

El trabajo realizado por los laicos en colaboración con los clérigos difusores del Catolicismo Social, permitió que la Iglesia tuviera una mayor influencia en las escuelas, en los hospitales y cárceles, así como en las relaciones laborales. Sin embargo, las actividades religiosas y sociales que habían estado llevando a cabo laicos y clérigos tuvieron que verse interrumpidos con las constantes políticas anticlericales que el gobierno callista implementó desde 1925, y que en 1926 culminaron con el inicio de un conflicto tanto armado como religioso. Dicho enfrentamiento, que no concluyó sino hasta 1929, truncó el avance del 
Catolicismo Social, especialmente en el ámbito laboral, pues la promulgación de la Ley orgánica del artículo 123 constitucional, promulgada en 1931 prohibió a los sindicatos toda denominación religiosa. Ello obligó a que las asociaciones de laicos tuvieran orientaciones distintas a partir de la conclusión del conflicto cristero, aunque la influencia de la Doctrina Social de la Iglesia continuó permeando en la organización sindical durante los años 30, si bien de forma subrepticia.

\section{Fuentes}

Archivo Histórico del Estado de Nuevo León (AHENL)

Asuntos Eclesiásticos (Religión)

Trabajo, Asociaciones y Sindicatos

Archivo Histórico de la Arquidiócesis de Monterrey (AHAM)

Boletín Eclesiástico del Arzobispado de Linares, 1908-1925

\section{Hemerográficas}

Acción. Órgano del Centro Regional de Monterrey de la Unión de Damas Católicas Mexicanas, 1922-1925

\section{Bibliográficas}

Abric, Jean-Claude, Prácticas sociales y representaciones. México, D.F., Ediciones Coyoacán, 2001.

Aguilar Camín, Héctor y Lorenzo Meyer, A la sombra de la Revolución Mexicana. México, Cal y Arena, 1990.

Álbum Conmemorativo del Solemne Congreso Eucarístico Nacional de México. Monterrey, N.L., Imprenta y Litografía Americana, 1924.

Blancarte, Roberto J., Historia de la Iglesia Católica en México. México, El Colegio Mexiquense/Fondo de Cultura Económica, 1996.

Ceballos Ramírez, Manuel, Historia de Rerum Novarum en México (1867-1931). Tomo I. México, D.F., Instituto Mexicano de Doctrina Social Cristiana, 2004. 
Saldaña Martínez, Moisés A., El anticlericalismo oficial en Nuevo León, 1924-1936. Monterrey, N.L., Facultad de Filosofía y Letras, Universidad Autónoma de Nuevo León, 2009.

Schell, Patience, "Las mujeres católicas del catolicismo social, 1912-1926", en: Ceballos, Manuel (coord.), Catolicismo Social en México. Las Instituciones, Tomo II. México, D.F., Instituto Mexicano de Doctrina Social Cristiana/Academia de Investigación Humanística, A.C., 2005.

Snodgrass, Michael, Deferencia y desafío en Monterrey: trabajadores, paternalismo y Revolución en México, 1890-1950. Monterrey, N.L., Fondo Editorial de Nuevo León, 2008.

Vellinga, Menno, Desigualdad, poder y cambio social en Monterrey. México, Siglo XXI, 1988. 